\title{
Sri Lanka Yellow Semi Tall; A new addition to the coconut (Cocos nucifera $\mathbf{L}$.) classification in Sri Lanka
}

L. C. J. Kamaral ${ }^{1}$, S. A. C. N. Perera ${ }^{1^{*}}$ and P. N. Dassanayaka ${ }^{2}$

${ }^{1}$ Genetics and Plant Breading Division, Coconut Research Institute, Lunuwila, 61150, Sri Lanka

${ }^{2}$ University of Sri Jayawardenepura, Gangodawila, Nugegoda

*Corresponding author: S. A. C.N.Perera,EEmail: chandrikaperera2003@yahoo.com

\begin{abstract}
In Sri Lanka, coconut (Cocos nucifera L.) has been classified into three varieties, typica, nana and aurantiaca based mainly on their stature and breeding behaviour. Typica and nana are tall and dwarf coconuts respectively while aurantiaca includes intermediate types. Different phenotypes within a variety have been classified as forms of coconut. Current Sri Lankan coconut classification includes 19 different forms within three varieties. There are four different forms of coconut within variety nana, as green, yellow, red and brown dwarfs based on the colour of the epicarp of the fruit. They all conform to the morphological features of variety nana except the yellow dwarf population which was observed to be a phenotypic mixture of different types of coconut. The current study was conducted to differentiate the phenotypes within the Sri Lankan Yellow Dwarf (SLYD) population and to classify them based on existing criteria. A sample of 200 yellow dwarf palms were studied to determine their breeding behaviour, and the morphological characteristics related to stem, leaf, inflorescence and fruit morphology and yield. Based on quantitative and qualitative data generated, the pure Sri Lanka yellow dwarf coconut form could be distinguished and in addition a new coconut form which was named as Sri Lanka Yellow Semi Tall (SLYST) which was classified within the variety aurantiaca, was identified within the yellow dwarf population. There was a further group of coconuts which could not be placed within the existing varietal classification and they were hypothesized to be a population resulting from cross pollination between SLYD and SLYST.
\end{abstract}

KEY WORDS: Coconut, genetic diversity, varietal classification 


\section{INTRODUCTION}

Coconut (Cocos nucifera L.) is the sole species of the genus Cocos belonging to the subfamily Cocoideae and lower group of flowering plants known as the monocotyledons. Based on breeding behaviour and stature of the palm, two groups of coconuts have been found around the world, namely, tall (typica) and dwarf (nana).

In Sri Lanka, coconut is classified into three varieties based on their stature and breeding behaviour. Accordingly, the Sri Lankan coconut classification includes tall (typica), dwarf (nana) and intermediate (aurantiaca) varieties (Liyanage, 1958). In this classification different morphotypes of coconut within varieties have been termed as forms. Consequently, 13 different forms within the three varieties of coconut were reported by Liyanage (1958). Variety typica included eight forms (Typica, Ran thembili, Gon thembili, Pora pol, Bodiri, Kamandala, Dikiri and Navasi); variety nana included three forms (Pumila, Regia and Eburnea) and variety aurantiaca included two forms (Thembili and Navasi thembili) in the initial classification. Later, coconut forms Rathran thembili, (variety aurantiaca); (Wickramaratne, 1984), Braune (brown dwarf; variety nana) (Perera et al., 1997) Rath Gon thembili (variety typica) Ran pol (variety typica), Juwan coconuts (variety typica) and Bothal thembili (variety aurantiaca) (Ekanayake et al., 2010) were introduced as new forms into the varietal classification of coconut in Sri Lanka increasing the number of different coconut forms to nineteen.

Palms belonging to variety typica (tall) are naturally out breeding. They are hardy palms and are tolerant to a wide range of environmental conditions. These plants flower in 5 to 6 years after planting and have an economic life span of more than 60 years under favourable conditions. Tall stature, larger crown and the presence of a prominent root bole are the gross morphological features of palms belonging to variety typica. Sri Lankan Tall is the most widely cultivated palm type and is grown in large scale plantations (Liyanage, 1955) in Sri Lanka.

Palms included in variety nana (dwarf) are short in stature and flower 3 to 4 years after planting. These palms are in-breeding and its economic life span is about 40 years. Shorter stature, smaller crown, bending frond tips and lack of a root bole are the gross morphological features differentiating tall coconuts and dwarf coconuts. This variety is very susceptible to environmental stresses and is not cultivated in large plantation. But dwarf variety plays a significant role in production of high quality hybrids which are used as planting material in Sri Lanka.

Variety aurantiaca (king coconuts) shows characters in between dwarf and tall. These plants are inbreeding and relatively early flowering. They commence flowering in 5 to 6 years after planting and display seasonality in flower production. Palms belonging to variety aurantiaca grow to an intermediate height and produce a prominent root bole at the base of the stem. This variety is also sensitive to moisture stress. Intermediate coconuts are very popular as beverage coconuts and are planted mainly in home gardens especially in wet and intermediate zones in the country. This variety of coconut is sometimes referred to as semi-tall.

Palms of the coconut form eburnea (Yellow dwarf) included in the variety nana, have been observed to display variations in morphological characters and deviate from typical yellow dwarf palms suggesting the 
yellow dwarf to be a mixed population. The present study was conducted with the objective of distinguishing the pure yellow dwarf coconut form and identifying/ classifying new coconut form/forms within the mixed yellow dwarf population based on morphological characters.

\section{MATERIALS AND METHODS}

Two hundred palms bearing yellow coloured nuts were randomly selected from the yellow dwarf mixed population planted at field number $10 \mathrm{~A}$ of Isolated Seed Garden, Ambakelle. The selected palms were first evaluated qualitatively for stem and crown morphological parameters; palm stature, presence or absence of a root bole, appearance of the crown and the nature of the frond tips. Based on the observed qualitative parameters the palms were categorized into three groups. Palms which were tall in stature, having root boles and with larger crowns with non-bending frond tips were included in the tall-like (TL) group. Palms with shorter stature, lacking a root bole and with smaller crowns ending with bending frond tips were categorized into dwarf-like (DL) group. The palms with mixed characters were excluded from further quantitative analysis.

Ten palms each of the TL and DL groups were observed for the duration of the male and female phases to determine their pollination behaviour. Furthermore, all the sampled palms in the visually discernible TL and DL groups were subjected to further analysis and were quantitatively evaluated for following morphologies (Table 01).

\section{Table 01: Quantitative morphological traits scored in the TL and DL palms}

Character Trait scored

Stem morphology

Stem girth at $20 \mathrm{~cm}$ above the soil level $(\mathrm{cm})(\mathrm{G} 20)$

Stem girth at $1.5 \mathrm{~m}$ height $(\mathrm{cm})(\mathrm{G} 150)$

Size of the bole (difference between the stem girth at 150 and 20

$\mathrm{cm}$ above the soil level)

Height of the stem $(\mathrm{cm})(\mathrm{SH})$

Crown morphology Rachis length (cm) (RL)

Fruit morphology $\quad$ Fresh fruit weight (g) (FFW)

(scored in 5 nuts in each palm) Kernal weight $(\mathrm{g})(\mathrm{KW})$

Polar circumference $(\mathrm{cm})(\mathrm{PC})$

Liquid endosperm weight (WW)

Equatorial circumference $(\mathrm{cm})(\mathrm{EC})$

Inflorescence morphology Number of female flowers (NFF) produced in an year

Number of inflorescences (NoIN) produced in an year

Yield

Nut count in mature six bunches (NC)

Students T-test was performed in MINITAB V16 statistical software to analyze the quantitative data in the two groups. 


\section{RESULTS AND DISCUSSION}

Based on the qualitative morphological features (palm stature, presence or absence of a root bole, appearance of the crown and the nature of the frond tips) the palms were classified into three groups. Out of the 200 palms 88 palms were included in the tall-like (TL) group, 58 palms in the dwarf-like (DL) group and 54 were identified to be in the group having mixed characters.

\section{Breeding behaviour}

Naturallyselfpollinatingbreedingbehaviour was confirmed in all the palms observed in the two groups, TL and DL. The male phase started on the day 01 of inflorescence opening and lasted for a minimum of 24 and a maximum of 28 days. The female phase started between $04^{\text {th }}$ to $10^{\text {th }}$ day of inflorescence opening and lasted for 09 to 18 days always overlapping with the male phase. Due to the overlapping of male and female phases it was observed that the intraspadix natural self pollination was facilitated in both TL and DL groups although a certain amount of out-crossing may happen because the receptive female flowers are exposed to the outside environment.

\section{Classification of the palms in the yellow dwarf population}

Stature and the breeding behaviour are the main characters used in the classification of coconuts in Sri Lanka into varietal groups (Liyanage, 1958). Accordingly, palms that were tall in stature, produce a root bole and are naturally cross pollinating due to nonoverlapping male and female phases in a single inflorescence, are included in the variety typica. In contrast, palms that are comparatively short in stature, lack a root bole and are naturally self pollinating due to overlapping of the male and female phases of the same inflorescence are included in the variety nana. The intermediate variety aurantiaca comprises of king coconut forms which have mixed characteristics; intermediate stature, presence of a root bole along with the self pollinating breeding behaviour (Table 02).

Table 02: Characteristics of the yellow dwarf coconut palms (TL \& DL) with reference to the three standard varieties, typica, nana and aurantiaca

\begin{tabular}{llllll}
\hline Character & Typica & Nana & Aurantiaca & DL group & TL group \\
\hline Stature & Tall & Dwarf & Intermediate & Dwarf & Intermediate \\
Bole & Present & Absent & Present & Absent & Present \\
Crown & Large & Small & Intermediate & Small & Intermediate \\
Frond tips & Rigid & Bending & Bending & Bending & Bending \\
$\begin{array}{l}\text { Breeding } \\
\text { behaviour }\end{array}$ & $\begin{array}{l}\text { Cross } \\
\text { pollinating }\end{array}$ & $\begin{array}{l}\text { Self } \\
\text { pollinating }\end{array}$ & $\begin{array}{l}\text { Self } \\
\text { pollinating }\end{array}$ & $\begin{array}{l}\text { Self } \\
\text { pollinating }\end{array}$ & $\begin{array}{l}\text { Self } \\
\text { pollinating }\end{array}$ \\
\hline
\end{tabular}


The DL group described above had characteristics typical of the nana variety. Therefore, DL palms within the yellow dwarf population were identified as the pure yellow dwarf coconut form, which is termed as Sri Lanka Yellow Dwarf (SLYD). The palms in the TL group displayed all the morphological features characteristic of coconuts in the variety aurantiaca. Therefore TL group of palms in the yellow dwarf population was classified as a new coconut form within variety aurantiaca. Based on the colour of the nut and the intermediate stature of the palm the new coconut form was named as Sri Lanka Yellow Semi Tall (SLYST).

Characterization of the TL \& DL palms based on quantitative morphological traits

As revealed by the t-test the two morphological groups; DL (SLYD) and TL (SLYST) differed significantly in all the quantitative characters scored representing, stem, leaf, inflorescence and fruit morphology, except for kernel weight, polar circumference and the number of female flowers, clearly differentiating the new coconut form SLYST from SLYD (Figures 1 - 12).

Consequently the novel coconut form SLYST is a coconut form which grows to an intermediate height and produces root boles at the base of the trunk. They possess longer rachis and larger crowns and bear heavier and more round shaped nuts compared to SLYD. In addition SLYST produces a higher number of inflorescences and bears more nuts than the SLYD as revealed by the results.

SLYST, the new addition to the Sri Lankan coconut classification will enrich the breeders' coconut collection in Sri Lanka and will assist in broadening the genetic base of coconut available among the conserved local coconut germplasm. This is a progressive step in coconut breeding which faced severe limitation in the past due to the limited genetic diversity identified within the local germplasm (Perera et al, 2010).

In addition to SLYD and SLYST there was another group of coconut palms having mixed characteristics of SLYD and SLYST. In any naturally self pollinating coconut variety there is a certain percentage of cross pollination because the female flowers of coconut at the receptive stage are exposed to the outside environment. This allows pollen produced in the surrounding palms to be carried by the wind and insects and to land on the receptive female flowers enabling cross pollination. Consequently, the cross pollination between SLYD and SLYST must have resulted in a progeny with mixed characteristics, which we have observed in the current study. 

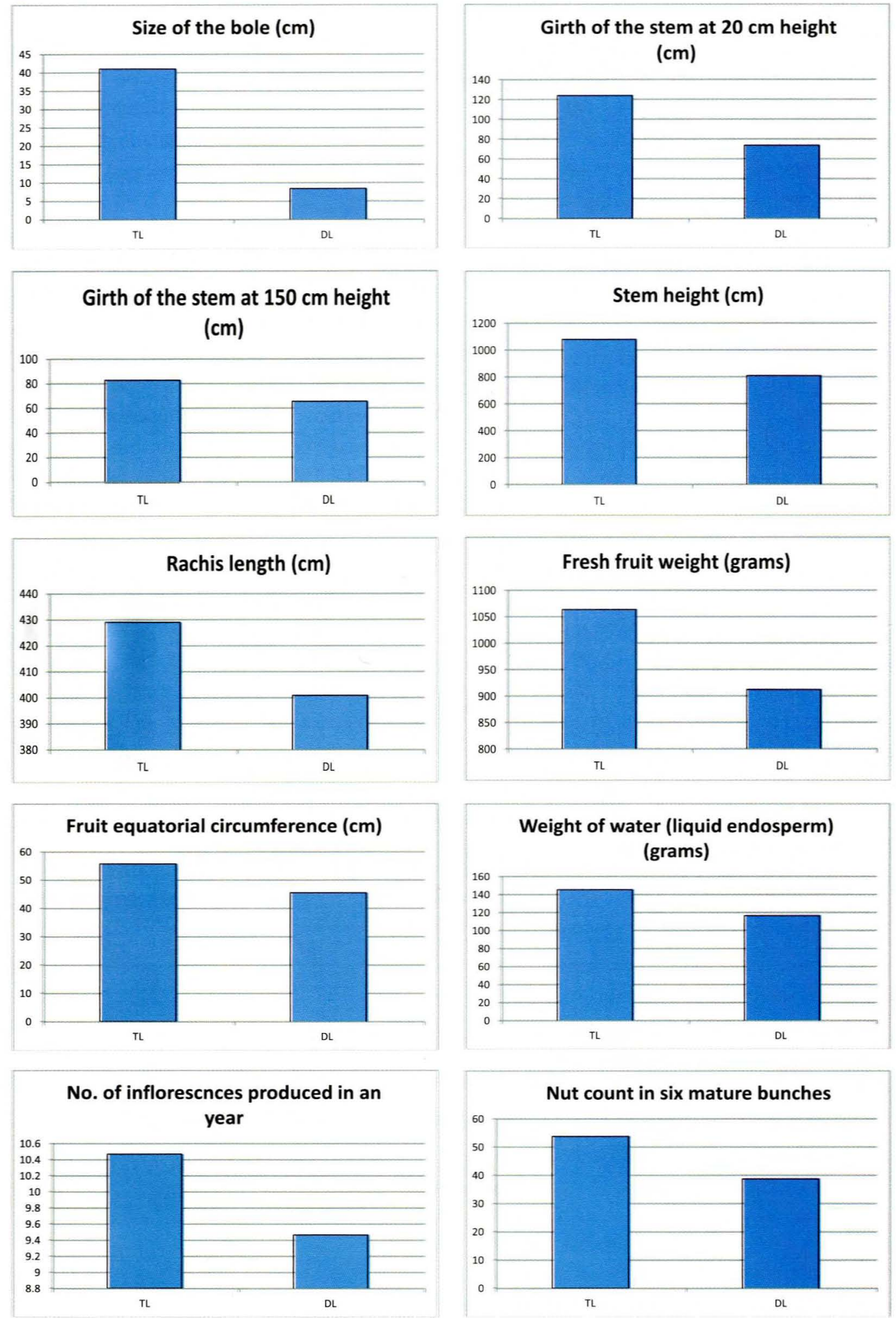

Figures 1-12: Statistically significant quantitative morphological parameters between SLYD and SLYST. 


\section{CONCLUSIONS}

The current study focused on distinguishing different coconut phenotypes from a mixed coconut population bearing nuts having yellow coloured epicarp. The coconut form Sri Lanka Yellow Dwarf was distinctly identified from the mixed population. In addition a new coconut form which was named as Sri Lanka Yellow Semi Tall could be identified and classified as a new coconut form included in variety aurantiaca.

\section{ACKNOWLEDGEMENTS}

We gratefully acknowledge the financial assistance of the National Research Council, Sri Lanka under grant number 11-042.The authors wish to acknowledge Head and the staff of Genetics and Plant Breeding Division, and Mr. Gamini Jayawardana of the Coconut Research Institute of Sri Lanka for their help in carrying out the experiment and in recording field data.

\section{REFERENCES}

Ekanayake G.K., Perera S.A.C.N., Dassanayaka K.P. and Everard J.M.D.T. (2010). Varietal classification of new coconut (Cocos nucifera) forms identified from Southern Sri Lanka. Cocos 19(1): 41-50.

Liyanage D.V. (1955). Planting materials for coconut. Ceylon coconut quarterly 6: 75-80.

Liyanage D.V. (1958). Varieties and forms of the coconut palm grown in Ceylon. Ceylon coconut quarterly 9: 1-10.

Perera L., Peries R.R.A. and Padmasiri M.H.L. (1997). Brown Dwarf: a recent addition to the varieties and forms of coconut palm grown in Sri Lanka. Cocos 12 (1): 82-84.

Perera S.A.C.N., Dissanayaka, H.D.M.A.C., Herath H.M.N.B., Chandrasiri S.A.S., Meegahakumbura M.G.M.K. and Perera L. (2010). Recently released coconut cultivars in Sri Lanka; A comparative evaluation. Proceedings of the Third Symposium on Plantation Crops Research. Colombo, Sri Lanka. pp 138-146.

Wickramaratne M.R.T. (1984). Report of the Genetics and Plant Breeding Division. In Report for 1984. Coconut Research institute of Sri Lanka. p. 45 